\title{
Computer simulation of the effects of anisotropic grain boundary energy on grain growth in 2-D
}

\author{
Shin-Woo Kim ${ }^{\dagger}$ \\ Dept. of Materials Engineering, Hoseo University, Asan 336-795, Korea
}

(Received July 2, 2012)

(Revised July 13, 2012)

(Accepted July 20, 2012)

\begin{abstract}
The grain growth is very important because of its great influence on the various materials properties. Therefore, in this study, the effects of anisotropic grain boundary energy on grain growth in 2-D have been investigated with a large scale phase field simulation model on PC. A $2000 \times 2000$ grid system and the initial number of grains of about 73,000 were used in the computer simulation. The anisotropic ratio of grain boundary energy, $\sigma_{\max } / \sigma_{\min }$, has been varied from 1 to 3. As the anisotropy increased, the grain growth exponent, $\mathrm{n}$, increased from 2.05 to 2.37 . The grain size distribution showed a central plateau in the isotropic case, and was changed into no central plateau and the increasing population of very small grains in the anisotropic case, resulting from slowly disappearing grains. Finally, simulated microstructures were compared according to anisotropy.
\end{abstract}

Key words Grain growth, Grain boundary energy, Anisotropy, Grain growth exponent, Phase field simulation

\section{이방성 결정립 계면에너지의 2차원 결정립 성장에 미치는 효과에 대한 컴퓨터 모사}

김신우 ${ }^{\dagger}$

호서대학교 신소재공학과, 아산, 336-795

(2012년 7월 2일 접수)

(2012년 7월 13일 심사완료)

(2012년 7월 20일 게재확정)

요 약 결정립 성장은 여러 가지 재료의 성질에 미치는 큰 영향으로 재료공학에서 매우 중요하다. 그래서 본 연구에서 는 $\mathrm{PC}$ 에서 대규모 상장 모델을 사용하여 이방성 결정립 계면에너지의 2차원 결정립 성장에 미치는 효과를 조사하였다. 컴 퓨터 모사에서는 $2000 \times 2000$ 의 그리드 시스템과 약 7300 개의 초기 결정립 개수가 사용되었다. 결정립계 에너지의 이방성 의 비, $\sigma_{\max } / \sigma_{\min }$ 는 1 부터 3 까지 변경되었다. 이방성이 증가함에 따라 결정립 성장 지수, $\mathrm{n}$ 은 2.05 에서 2.37로 증가하였다. 결 정립 크기의 분포는 등방성인 경우에는 중앙에 평탄한 영역을 보였으나 이방성의 경우에는 중앙의 평탄한 영역이 사라지 고 매우 느리게 사라지는 작은 결정립에 기인하여 작은 결정립 크기의 분포가 약간 증가하였다. 마지막으로 모사된 결정립 미세구조가 이방성에 따라 비교, 분석되었다.

\section{1. 서 론}

결정립 성장은 재료의 총 결정립 계면에너지를 줄이기 위해서 일어나는 자연적인 현상으로 재료의 여러 가지 물리적, 화학적, 전기적, 기계적 성질에 중요한 영향을 미친다. 그중에서도 재료공학에서 가장 잘 알려져 있고

\footnotetext{
Corresponding author

Tel: +82-41-540-5764

Fax: +82-41-548-3502

E-mail: swkim@hoseo.edu
}

산업에 널리 이용하고 있는 현상은 재료의 강도를 향상 시키기 위해서 결정립을 미세화 시키는 것이다. 최근에 는 나노 제조기술과 분석기술의 발달로 마이크로 크기에 서 나노 크기의 결정립으로 미세화 하는 것이 용이하게 이루어져 단지 재료의 미세구조를 변화시켜서 재료의 강 도를 비약적으로 향상시키는 것이 가능해지고 있다. 그 러나 이러한 뛰어난 기계적 성질을 가지는 나노 재료는 결정적으로 높은 결정립 계면에너지를 가지고 있기 때문 에 필수적으로 고온에서는 결정립 성장이 일어나 기계적 성질이 떨어지는 현상이 발생하게 된다. 그래서 이러한 
Table 1

Grain growth exponents in metals and ceramics

\begin{tabular}{ll}
\hline Materials & Grain growth exponent, $\mathrm{n}$ \\
\hline $\mathrm{Al}$ & 4 \\
$\mathrm{Fe}$ & 2.5 \\
$\mathrm{~Pb}$ & 2.5 \\
$\mathrm{Sn}$ & 2.3 \\
$\mathrm{ZnO}$ & 3 \\
$\mathrm{MgO}$ & 2 \\
$\mathrm{CdO}$ & 3 \\
$\mathrm{Ca}_{0.16} \mathrm{Zr}_{0.84} \mathrm{O}_{1.84}$ & 2.5 \\
\hline
\end{tabular}

현상을 방지 또는 지연시키기 위한 방법을 찾기 위해서 최근에 다시 결정립 성장에 관한 연구가 많이 이루어지 고 있는 실정이다[1-9]. 특히 최근에는 컴퓨터 성능의 비 약적인 발달로 여러 가지 컴퓨터 모사법(computer simulation)을 이용하여 결정립 성장에 관한 수치 해석적 연구가 활발히 이루어지고 있다[10-17].

결정립 성장과 재료 물성의 밀접한 관계로 지난 수십 년간 결정립 성장에 관하여 무수히 많은 이론적, 실험적 연구가 이루어져 왔으나 아직도 풀어야할 많은 문제를 가지고 있다. 그중에 하나가 다음과 같은 평균 결정립 크기, $<\mathrm{R}>$ 과 시간, $\mathrm{t}$, 사이의 관계식에 나오는 결정립 성장 지수, $\mathrm{n}$, 값이다.

$$
\langle\mathrm{R}\rangle^{\mathrm{n}}-\left\langle\mathrm{R}_{\mathrm{o}}\right\rangle^{\mathrm{n}}=\mathrm{ct}
$$

여기서 $<\mathrm{R}>$ 은 시간 $\mathrm{t}$ 에서의 평균 결정립의 크기, $\left\langle\mathrm{R}_{0}>\right.$ 는 초기 평균 결정립의 크기, $\mathrm{t}$ 는 시간, c는 상수이다. 결정립 계면에너지가 일정하고(즉, 등방성 결정립 에너 지), 결정립계의 이동속도가 결정립 크기, $\mathrm{R}$ 의 역수에 비례한다는 이상적인 가정 하에 유도된 대부분의 결정립 성장 관계식은 $\mathrm{n}=2$ 를 예측하고 있다. 그러나 실험적으 로 측정된 $\mathrm{n}$ 값은 Table 1 과 같이 순수한 금속 및 합금 에서 대부분 2 보다 큰 값을 보이고 있다[18]. 이러한 이 론과 실험값의 차이는 실제 재료에서는 결정립 계면에너 지의 이방성, 불순물에 의한 효과, 석출물의 효과, 입계 편석의 효과 등 여러 가지 다른 요소들이 복합적으로 영 향을 미치는 것으로 생각되어진다. 그래서 본 연구에서 는 최근에 재료의 여러 가지 현상을 해석하는데 널리 사 용되고 있는 상장(Phase Field) 모델을 이용하여 이방성 결정립 계면에너지가 결정립 성장에 미치는 효과를 조사 하였다.

\section{2. 모사방법}

결정립 성장에 관한 수치해석 방법에는 몬테칼로법 [15-17]이 주로 사용되어왔으나 계산결과에 대한 정량적
해석이 불분명한 등의 문제점으로 현재는 상장(Phase Field) 모델을 사용한 수치해석 방법이 널리 사용되고 있 다. 그래서 본 연구에서는 최근에 S.G. Kim 등[13]에 의 하여 이상적인(Ideal) 결정립 성장에 관하여 개발된 상장 모델 코드를 이용하여 이방성 결정립 계면에너지가 결정 립 성장에 미치는 효과를 조사하였다. 그들의 모델에 사 용된 상장이론의 자세한 배경과 기본 방정식은 참고문헌 [13]에 자세히 설명되어 있다. 결정립 성장의 해석에서는 많은 결정립 방위(Orientation)의 개수가 필요한 것에 기 인하여 계산시간과 컴퓨터 메모리의 용량이 상당히 요구 되기 때문에 그동안 연구에서는 허용되는 결정립의 방위 의 개수가 상당히 제한되는 문제점이 있었다. 그러나 이 모델의 가장 큰 특징은 하나의 그리드에 존재하는 결정 립 방위의 개수를 최대 6으로 최소화하는 새로운 알고 리즘을 도입하여 계산시간과 메모리 용량을 대폭 감소시 켜 대규모 결정립 개수의 시스템 계산을 간단히 $\mathrm{PC}$ 상에 서 가능하도록 하였다.

그래서 본 연구에서는 계산의 크기를 $2000 \times 2000$ 그 리드 시스템으로 하였으며 초기 결정립의 개수는 대략 73000 정도를 사용하였다. 수치계산은 Intel Core $2 \mathrm{CPU}$ $(2.13 \mathrm{GHz})$ 의 $\mathrm{PC}$ 를 사용하여 8000 시간스텝을 하는데 대략 30 시간 정도의 계산시간이 소요되었으며 결정립의 개수는 대략 3500 정도로 감소되었다. 그리고 결정립 계 면에너지의 이방성의 비, $\sigma_{\max } / \sigma_{\min }$ 는 $1,1.5,2,3$ 의 4 가 지 경우에 대하여 각각 계산을 수행하였다.

\section{3. 결과 및 고찰}

Fig. 1은 계산 시간스텝 수에 따른 평균 결정립 크기 의 변화를 보여주는 그래프로 8000 시간스텝까지의 평

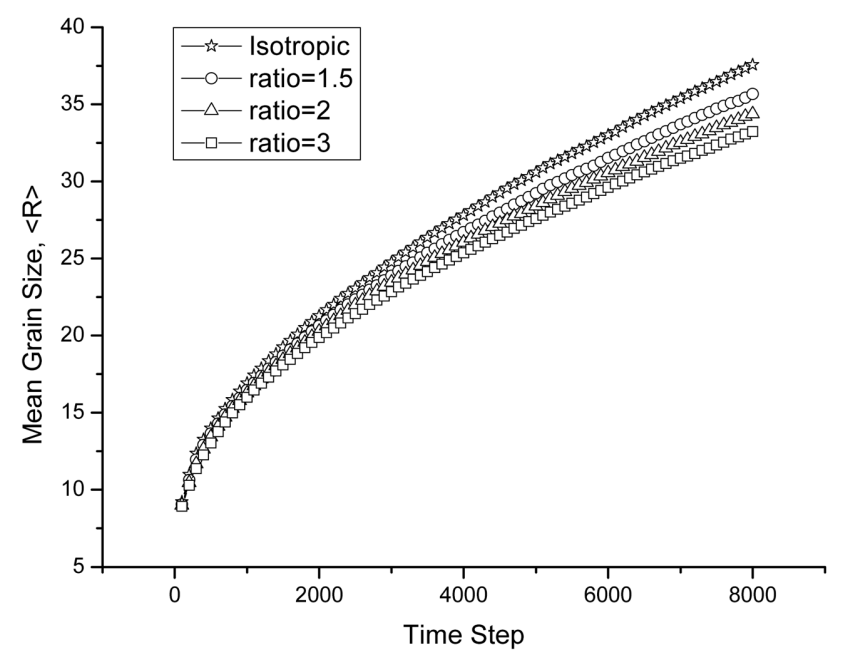

Fig. 1. Plot of mean grain size against time steps for anisotropic ratio of grain boundary energy, $\sigma_{\text {max }} / \sigma_{\text {min }}$. 
균 결정립 크기의 성장변화를 나타낸다. 우선 결정립계 면에너지의 이방성의 비가 $\sigma_{\max } / \sigma_{\min }=1$ 인 경우 즉, 등방 성 결정립인 경우에 시간에 따른 평균 결정립 크기가 가 장 크고 이방성의 비가 $\sigma_{\max } / \sigma_{\min }=3$ 인 경우에 평균 결정 립 크기가 가장 작은 것을 알 수 있었다. 즉, 결정립 이 방성의 정도가 증가함에 따라 결정립 성장이 느리게 되 어 평균 결정립 크기가 감소하는 경향을 보이는 것으로 판단된다.

Table 2

Grain growth exponents according to the anisotropic ratio of grain boundary energy, $\sigma_{\max } / \sigma_{\min }$

\begin{tabular}{ll}
\hline$\sigma_{\max } / \sigma_{\min }$ & Grain growth exponent, $\mathrm{n}$ \\
\hline 1 & 2.0585 \\
1.5 & 2.1637 \\
2 & 2.2960 \\
3 & 2.3677 \\
\hline
\end{tabular}

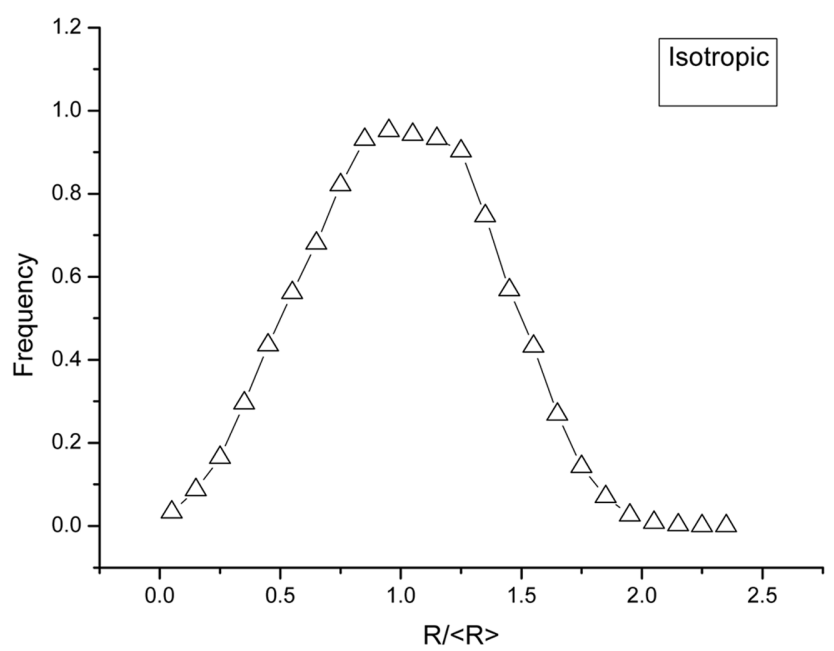

(a) ratio $=1$

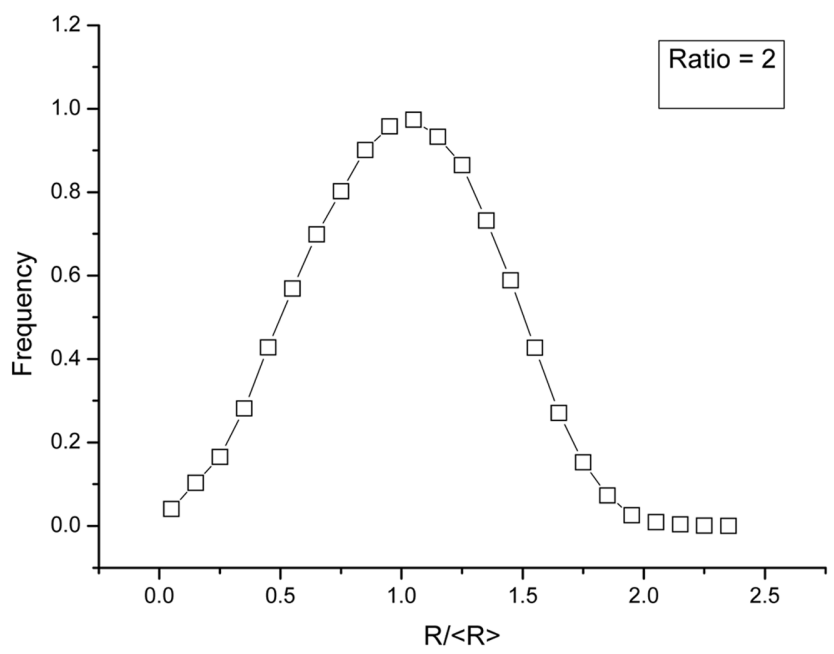

(c) ratio $=2$
Fig. 1 의 4가지 경우의 데이타를 각각 결정립 성장방 정식(1)에 대입하여 결정립 성장지수, $\mathrm{n}$ 값을 구하면 Table 2 와 같이 주어진다. 이방성의 비가 1 인 경우 즉, 등방성 결정립계인 경우에 계산되어진 결정립 성장 지수 는 $\mathrm{n}=2.0585$ 로 이상적인 가정하에서 유도된 이론적 값, $\mathrm{n}=2$ 와 거의 같은 것을 확인할 수 있다.

그리고 이방성의 정도가 증가함에 따라 결정립 성장 지수, $\mathrm{n}$ 도 같이 증가하는 것을 알 수 있으며 Table 1 의 실제 재료에서 실험적으로 측정된 결정립 지수가 대부분 2 보다 큰 값을 보이는 중요한 원인이 결정립 계면에너지 의 이방성이라는 것을 확인을 할 수 있다.

Fig. 2 는 4 가지 경우의 결정립 계면에너지 이방성의 비에 해당하는 결정립 크기 분포를 보여주는 그래프이다. 여기서 $x$ 축은 평균 결정립의 크기로 표준화된 결정립의 크기를 나타내고 $\mathrm{y}$ 축은 각 해당되는 결정립 크기의 빈 도수를 나타낸다. 우선 Fig 2(a)의 이방성의 비가 $\sigma_{\max } I$

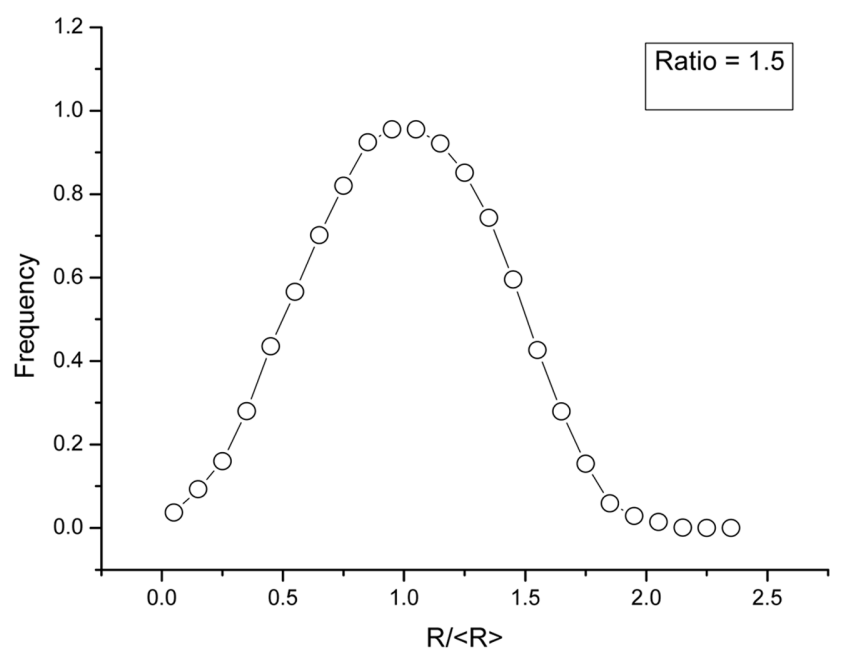

(b) ratio $=1.5$

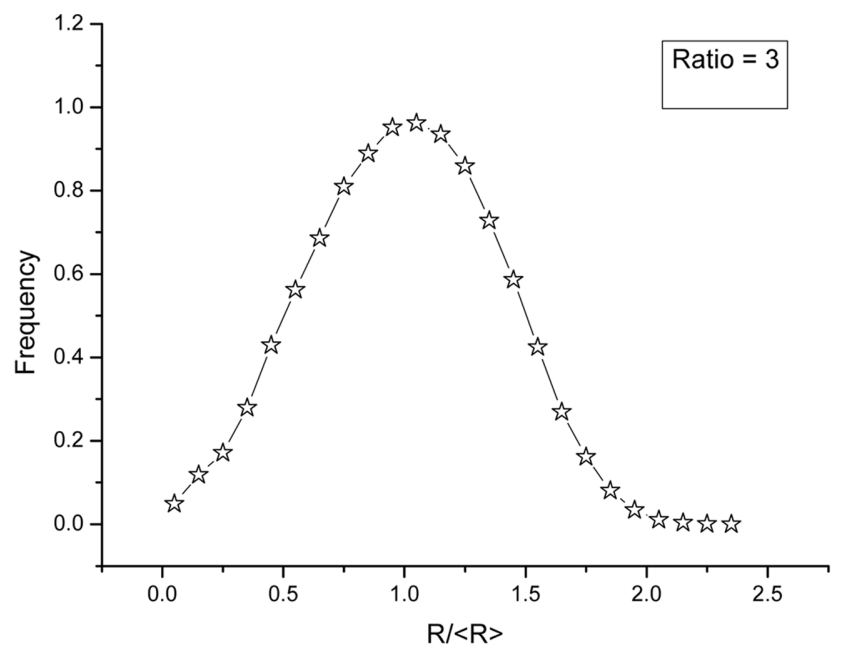

(d) ratio $=3$

Fig. 2. Grain size distributions after 8000 time steps for anisotropic ratio of grain boundary energy, $\sigma_{\max } / \sigma_{\min }$ : (a) ratio $=1$ (b) ratio $=1.5$ (c) ratio $=2$ (d) ratio $=3$. 
$\sigma_{\min }=1$ 인 경우 즉, 등방성 결정립 계면에너지인 경우에 는 S.G. Kim 등[13]에 의하여 잘 보여준 것과 같이 평 균 결정립 크기 근처에서 최대 분포를 보이며 평탄한 영 역이 존재하였다. 그러나 Fig. 2(b) (d)와 같이 이방성의 비가 $\sigma_{\max } / \sigma_{\min }=1.5,2,3$ 인 경우에는 거의 유사한 결정 립 크기 분포를 보이며 등방성 에너지인 경우와는 다르 게 평균 결정립 근처에 나타나는 평탄한 영역이 사라지 고 아주 작은 크기의 결정립들의 분포가 다소 증가한 것 을 알 수 있었다. 이것은 결정립 계면의 이동속도, $\mathrm{v}$ 가 다음 관계식과 같이 결정립의 계면에너지에 비례하는데 이방성의 경우에는 결정립 계면에너지가 큰면에서는 등 방성의 경우보다 빠르게 이동하지만 에너지가 작은 면에 서는 등방성의 경우보다 훨씬 느리게 이동하게 되어 결 과적으로 작은 결정립이 사라지는 속도가 등방성의 경우 보다 느리게 되어 작은 결정립의 크기분포가 다소 증가 하게 되고 결정립 개수의 감소도 느리게 되어 평균 결정
립의 크기가 감소하게 되는 것으로 판단되어진다.

$$
\mathrm{v}=\frac{\mathrm{dR}}{\mathrm{dt}}=\frac{2 \mathrm{M} \sigma}{\mathrm{R}}
$$

여기서 $\mathrm{M}$ 은 결정립 계면의 이동도, $\sigma$ 는 결정립 계면에 너지, R은 결정립 계면의 곡률반경을 나타낸다.

Fig. 3은 8000 시간스텝후의 전형적인 2차원의 결정립 미세구조를 보여준다. 이방성의 비가 1 인 등방성 에너지 인 경우에는 Fig. 2(a)와 같이 결정립들이 만나는 삼중 점(Triple Junction)에서 평형을 유지하기 위하여 $120^{\circ}$ 의 각도를 거의 정확히 유지하는 것을 알 수 있으나 이방성 인 경우에는 에너지 이방성에 기인하여 삼중점에서 $120^{\circ}$ 를 벗어나는 경우가 많은 것을 알 수 있다. 그래서 이방 성의 정도가 증가함에 따라 휘어진 결정립계를 가지는 결정립들이 많이 보이는 이유이며 이것이 또한 결정립 계면의 이동속도와 결정립 성장을 느리게 하는데 크게

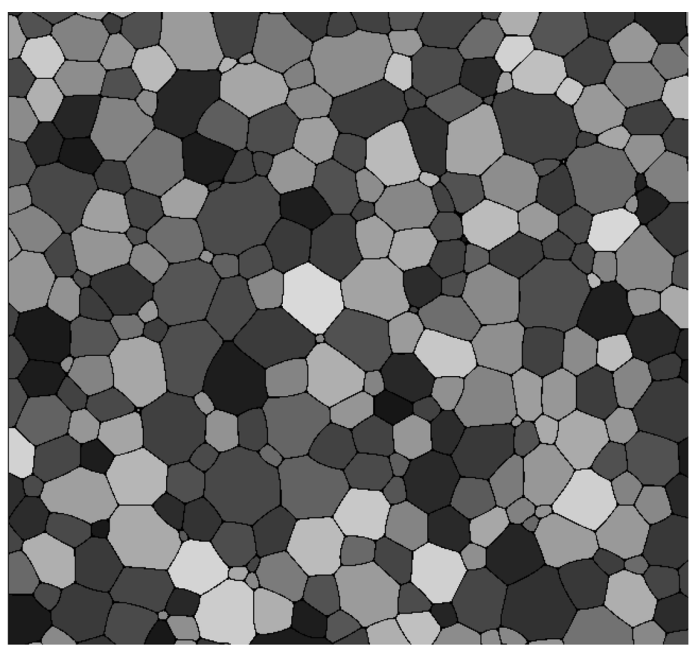

(a) ratio $=1$

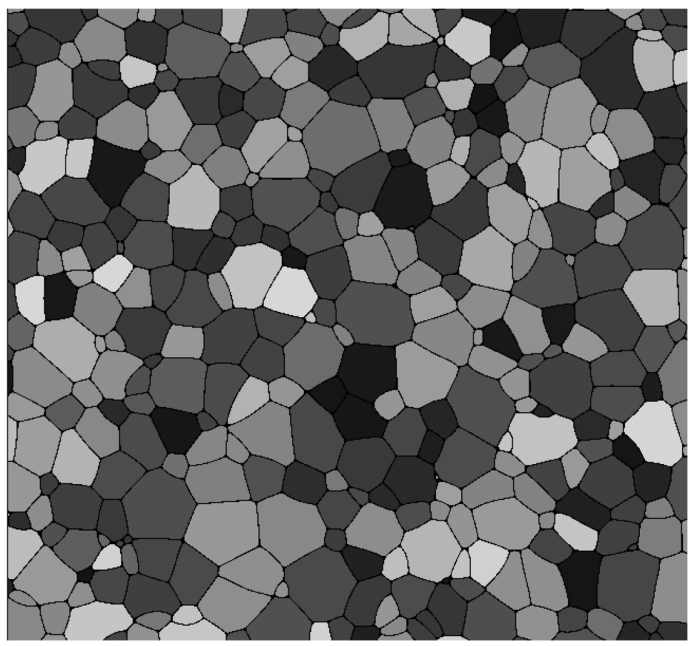

(c) ratio $=2$

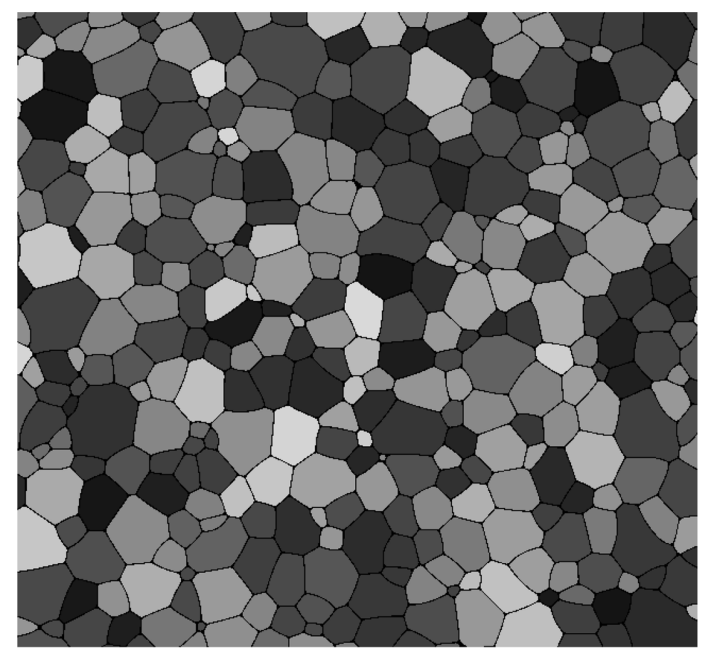

(b) ratio $=1.5$

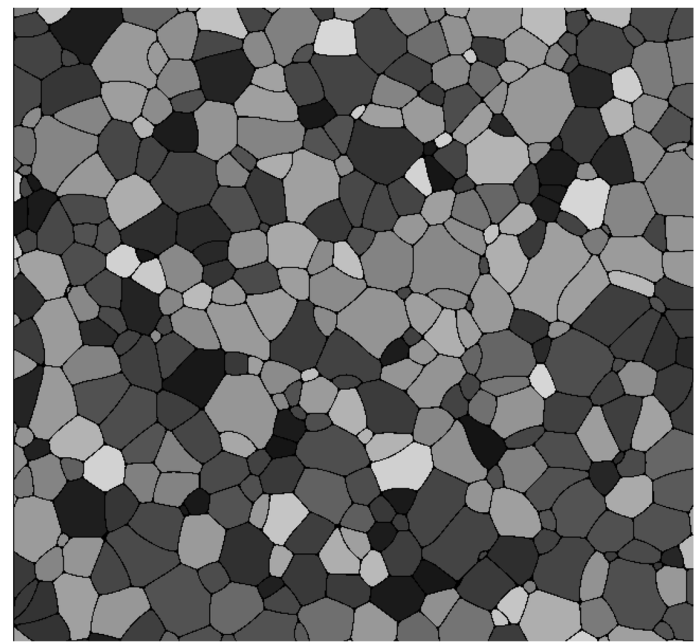

(d) ratio $=3$

Fig. 3. Microstuctures after 8000 time steps for anisotropic ratio of grain boundary energy, $\sigma_{\max } / \sigma_{\min }$ : (a) ratio $=1$ (b) ratio $=1.5$ (c) ratio $=2$ (d) ratio $=3$. 
영향을 미치는 것으로 생각되어진다.

\section{4. 결 론}

본 연구에서는 최근에 S.G. Kim 등에 의하여 개발된 상장(Phase Field) 모델 코드을 이용하여 이방성 결정립 계면에너지가 결정립 성장에 미치는 효과를 컴퓨터 모사 를 통하여 조사한 결과 다음과 같은 결론을 얻었다.

1) 결정립 계면에너지의 이방성의 비가 증가함에 따라 결정립 성장이 다소 느려지고 평균 결정립 크기가 감소 하는 경향을 보였다.

2) 이방성의 비가 증가함에 따라 결정립 성장 지수, $n$ 이 2.05에서 2.38로 증가하였으며 실험적으로 측정된 결 정립 지수가 대부분 2 보다 큰 값을 보이는 중요한 원인 이 결정립 계면에너지의 이방성이라는 것을 확인하였다.

3) 결정립 크기의 분포는 등방성인 경우에는 중앙에 평탄한 영역을 보였으나 이방성의 경우에는 중앙의 평탄 한 영역이 사라지고 작은 결정립 크기의 분포가 약간 증 가하였다.

4) 등방성 에너지인 경우에는 결정립들이 만나는 삼중 점(Triple Junction)에서 $120^{\circ}$ 의 각도를 정확히 유지하였 으나 이방성인 경우에는 삼중점에서 $120^{\circ}$ 를 벗어나는 경 우가 많아 휘어진 결정립계를 가지는 결정립들이 많이 보였으며 이것은 결정립 계면의 이동속도와 결정립 성장을 느리게 하는데 큰 영향을 미치는 것으로 생각되어진다.

\section{감사의 글}

본 논문은 호서대학교 학술연구조성비에 의하여 연구 되었으며 결정립 성장에 관한 상장모델의 코드를 사용하 도록 허락해 주신 군산대학교 김성균 교수에게 깊은 감 사를 드립니다.

\section{참 고 문 헌}

[1 1 E.A. Holm and S.M. Foiles, "How grain growth stops: A mechanism for grain-growth stagnation in pure materials", Science 328 (2010) 1138.

[2 2 P.R. Rois and M.E. Glicksman, "Polyhedral model for self-similar grain growth", Acta Mater. 56 (2008) 1165.
[3] J. Svoboda and F.D. Fischer, "A new approach to modelling of non-steady grain growth", Acta Mater. 55 (2007) 4467.

[4] T. Wejrzanowski, K. Batorski and K.J. Kurzydlowski, "Grain growth modelling: 3D and 2D correlation", Materials Characterization 56 (2006) 336.

[5] C.S. Pande and A.K. Rajagopal, "Modeling of grain growth in two dimensions", Acta Mater. 50 (2002) 3013.

[6] A. Kazaryan, B.R. Patton, S.A. Dregia and Y. Wang, "On the theory of grain growth in systems with anisotropic boundary mobility”, Acta Mater. 50 (2002) 499.

[ 7 ] P.R. Rios, "Irreversible thermodynamics, parabolic law and self-similar state in grain growth", Acta Mater. 52 (2004) 249.

[ 8 ] S. Yoon, J. Kim, B. Shin, S. Park, D. Shin and H. Lee, "Effects of anatase-rutile phase transition and grain growth with $\mathrm{WO}_{3}$ on thermal stability for $\mathrm{TiO}_{2}$ SCR catalyst", J. of Kor. Cryst. Growth \& Cryst. Tech. 21 (2011) 181.

[9] S. Kim, E. Kang, U. Kim, K. Hwang and W. Cho, "Sintered body characteristics of LAS by addition of $\mathrm{CaCO}_{3}$ and $\mathrm{ZrO}_{2}$ using a solid-state reaction”, J. of Kor. Cryst. Growth \& Cryst. Tech. 21 (2011) 218.

[10] N. Moelans, F. Wendler and B. Nestler, "Comparative study of two phase-field models for grain growth", Computational Materials Science 46 (2009) 479.

[11] N. Moelans, B. Blanpain and P. Wollants, "An introduction to phase-field modeling of microstructure evolution", Computer Coupling of Phase Diagrams and Thermochemistry 32 (2008) 268.

[12] V.Y. Novikov, "Microstructure stabilization in bulk nanocrystalline materials: Analytical approach and numerical modeling", Mater. Lett. 62 (2008) 3748.

[13] S. Kim, D. Kim, W. Kim and Y. Park, "Computer simulations of 2D and 3D ideal grain growth", Phys. Rev. E 74 (2006) 061605.

[14] C.E. Krill and L.Q. Chen, "Computer simulation of 3-D grain growth using a phase-field model", Acta Mater. 50 (2002) 3057.

[15] Q. Yu and S.K. Esche, "Three-dimensional grain growth modeling with a monte carlo algrithm", Mater. Lett. 57 (2003) 4622.

[16] M.P. Anderson, D.J. Srolovitz, G.S. Grest and P.S. Sahni, "Computer simulation of grain growth-I. kinetics", Acta Mater. 32 (1984) 783.

[17] D.J. Srolovitz, M.P. Anderson, P.S. Sahni and G.S. Grest, "Computer simulation of grain growth-II. Grain size distribution, topology, and local dynamics", Acta Mater. 32 (1984) 793.

[18] F.J. Humphreys and M. Hatherly, "Recrystallization and related annealing phenomena", 2nd Ed., Elsevier, p. 338 (2004). 